\title{
Streamlining Building Information Model creation using Agile project management
}

\author{
S. Suresh Kumar \& J. J. McArthur \\ Department of Architectural Science, Ryerson University, Canada
}

\begin{abstract}
Building Information Modelling (BIM) offers tremendous advantages to multidisciplinary teams from a coordination standpoint throughout the project lifecycle. That said, there are potential pitfalls with the use of BIM if coordination and communication between the disciplines is not properly managed, resulting in rework and inefficiencies in delivery. Agile project management techniques, widely adopted within the software industry to allow incremental development of products, have great potential for application to BIM model development throughout the project lifecycle. These techniques focus on simple and regular communication between core project members and stakeholders, regular priority identification to set the goals for the next phase ("Sprint") and incremental product development. Applied to BIM model development, these techniques provide a framework for multi-disciplinary coordination and interface management and reduce re-design and abortive effort from miscommunication and poor task sequencing.

This paper presents two case studies to demonstrate the effectiveness of this approach. In the first, an Architectural BIM model was created at schematic design and these techniques were used to guide the development of the design and the associated BIM model. In the second, a BIM model was created during the operational phase of a building to consolidate the data from a variety of facilities management and operations systems (maintenance, asset management, health and safety, sustainability and space planning). In each, the various stakeholders are consulted to set priorities for model development, which are incrementally implemented. These case studies demonstrate the benefits of using an Agile approach to BIM and inform the framework presented in this paper.

Keywords: BIM, Agile project management, multi-disciplinary design.
\end{abstract}




\section{Introduction}

The diversity of use of Building Information Modelling (BIM) in design and construction has been well-documented [1,2]. BIM has multiple definitions but is well-summarized as "an integrated model in which all process and product information is combined, stored, elaborated, and interactively distributed to all relevant building actors" [3].

While guidelines exist for BIM planning, e.g. [4], the step-by-step process for designing a building using BIM model is not prescribed. It is the goal of this paper to present a framework that guides the managed and integrated development of Building Information Models (BIMs) for both design and operations applications.

This paper proposes the application of Agile [5] project management techniques, particularly a modified Sprint process, to BIM in order to maximize collaboration, documentation and lifecycle data management, design refinement and interactive distribution (end-user feedback). To demonstrate this methodology, two case studies have been developed: the architectural design of a multi-use library complex from schematic to detailed design, and the development of a Sustainable Operations BIM for an academic building at Ryerson University.

\section{Literature review}

While BIM has been used for a wide range of use cases and project activities, in this paper we have considered BIM in three key roles: (1) as a visualization/ communication tool (including inter-discipline coordination); (2) as a design and analysis tool; and (3) as the repository of project life-cycle information. Research has demonstrated that BIM is an important visualization and coordination tool [6, 7] as well as stakeholder communication [8] and collaboration [9]. As such, it provides a means for the transfer of both geometric and non-geometric data to a wide array of stakeholders and project participants and facilitates collaboration throughout the project life cycle. Design is a primary function driving BIM software, while analysis using BIM has become widely adopted, particularly to improve the sustainability of a building during the design phase $[10,11]$ and is a topic of current research e.g. [12] as it improves the triple bottom line of a building project [13].

Over the building life cycle, BIM enables the transfer of information between stakeholders (summarized in [14] and can be structured to provide stakeholders with a useful repository of both geometric and non-geometric data $[3,14,15]$.

The Agile methodology is based on a set of values developed at a meeting of software developers in 2001 [7] to provide a more participant-centric, flexible and iterative approach to software than more traditional sequential approaches. The core values of the Agile movement are summarized as "individuals and interactions over processes and tools, working (software) over comprehensive documentation; customer collaboration over contract negotiation, and responding to change over following a plan" [7]. Agile enablers [16] have substantial overlap with architectural design practice, such as obtaining regular customer feedback, focusing on clarity and simplicity in communication, and communication through 
visual rather than written means [17]. A case study [18] investigating BIM implementation into lean architectural practice integration with energy assessment tools (analysis), coordination and concurrent work (communication), virtual reality (visualization) and flexibility to satisfy customers as key benefits.

Other research [19] characterized building design by iteration (rework) and found that accelerating the design cycle involves either faster iterations using improved coordination tools, integration of engineering analysis, and eliminating unnecessary activities; and/or fewer iterations, through activity decoupling and improved activity sequencing. Faster iterations (Sprints) are enabled by the use of $\mathrm{BIM}$ as a design, analysis and coordination/communication tool, while Sprints decouple and improve the sequence of activities to reduce the number of iterations.

This approach, while originating within the software development field, is being increasingly considered for adoption in other fields [16], and is similar to the lean construction and Agile manufacturing approaches used in the industry. Agile manufacturing is "the ability to thrive in a competitive environment of continuous and unpredictable change, requiring quick reactions and driven by customer-designed products and services" [20], which has strong parallels with the building design process. Other enabling elements of Agile Manufacturing overlapping with BIM include concurrent engineering, computer-aided drafting, manufacturing, and engineering (CAD/CAM/CAE), and rapid design and prototyping [21]. Because of its strong emphasis of collaboration and responsiveness, there is no single fixed set of processes that define Agile, however a key technique of interest to this paper is the Sprint, an iterative process whereby the end-product is defined based on a number of desired functionalities (called "user stories") and each iteration (Sprint) focuses on the delivery of one or more of these functionalities to maximize utility for end-users, within a set of constraints. The two goals of this process are to achieve customer satisfaction and risk management. The former is addressed partly by delivering the highest-value functionality first, while the latter is achieved by considering deficiencies to avoid late side-effects (changes) [22].

\section{Agile BIM development}

BIM can be used in three complementary ways: visualization, design, analysis and documentation, and these can be effectively used as part of an iterative approach. Each design iteration focuses on either adding a new design element, refining design elements (based on analysis), removing design element(s) and/or increasing level of detail of design element(s).

Regular meetings with the client follow a loose Sprint meeting structure including presentation of progress, client feedback and evaluation stages referred to in Figure 1. Each Sprint iteration is focused on one or more of three types of tasks: (1) the addition of a new design element, (2) the refinement (or deletion) of an existing design element, and (3) increasing the level of detail (LOD) of a design element in the model. In the case of a successful sprint phase future priorities were identified and new goals were set for the upcoming sprint phase. In the case of an 
unsuccessful sprint phase past measures were reviewed and future goals were set based on the information gathered from the re-tracing of steps.

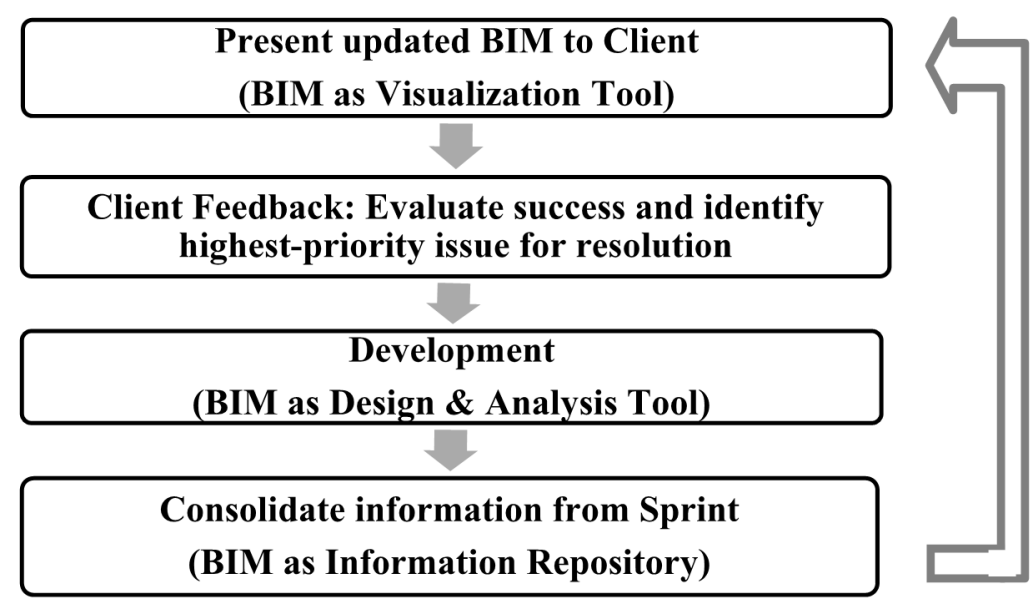

Figure 1: Sprint process diagram.

\section{Case study: design}

The design phase case study considered the design of a multi-use complex incorporating an office, library and community facilities through detailed design. This design process was intended to provide a real, workable building design for an actual site in Toronto, Canada, and occurred within an academic studio environment from September 2014 through April 2015. The schematic design stage occurred from September-December 2014 and design development started in January 2015.

Early in the design development stage, significant changes (removal of an exterior courtyard, modification of entrance locations; and revised floorplans) were made to the building as a whole, whereas the latter part of this period focused more on element refinement as illustrated in Figure 2. This case study is focused primarily on the refinement of one particular element, a large external stair highlighted in Figure 2(b), that was brought from LOD 100 up to LOD 400 over this period.

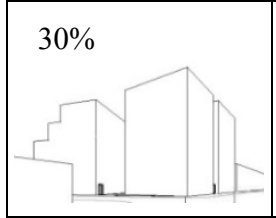

(a)

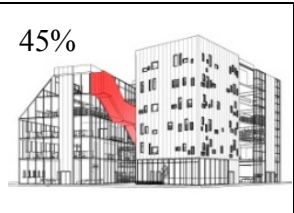

(b)

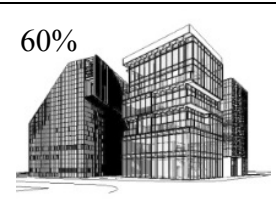

(c)

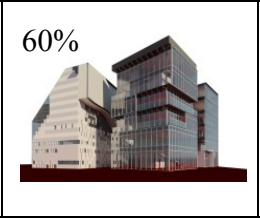

(d)

Figure 2: $3 \mathrm{D}$ views of library at various stages in design. 


\subsection{Communication and collaboration techniques}

The Architectural designers interacted in three key ways: stand-up meetings every 1-2 days; client meetings, and (3) input from other disciplines. Stand-up meetings were either short (5-10 minutes) or design charrettes (30 minutes to 2 hours). The goals of these meetings were to arrive at solutions for issues addressed, determine the schedule, and determine the LOD for the upcoming documentation.

Interaction with the client occurred in three different forms: collaborative working sessions, informal presentations, and design reviews. Collaboration sessions began with a presentation of the updated BIM model (live and printed views) to evaluate the success of the previous Sprint. Next, further issues were investigated, potential solutions discussed, and priorities set for the next Sprint. In these sessions, BIM was used as both a visualization/communication tool as well as a design tool for option investigation. During informal presentations, the evaluation and priority-setting processes were the same, but BIM was used for visualization and communication only. Finally, in formal reviews, additional senior-level consultants provided feedback on the design progress, which informed the next collaboration session. Agile checklists based on [26] framed the above converstaions and were initially followed strictly for these meetings, but it was soon apparent that the process was taking over, in conflict with Agile values [7] and the process was modified to use these as guides to frame the conversations rather than strict procedures.

Input from other disciplines and $3^{\text {rd }}$ party analysis software used in this phase included an energy analysis simulated in Revit (Figure 3) to analyse loads required for the building to perform with the current envelope system, shadow studies to document interior space experience affected by location and form of building as well as input from a mechanical engineer to provide insight on best practice choices for the mechanical system and layout used.

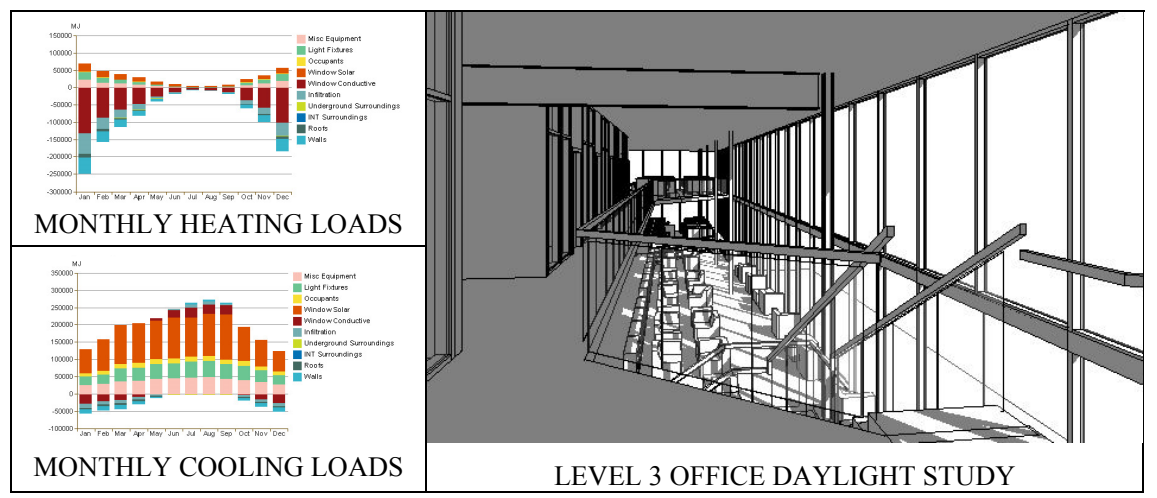

Figure 3: Energy analysis and daylighting study. 


\subsection{Sprint structure}

Due to the constant iteration and development that characterizes architectural design, accelerated Sprints were used, each lasting 2-5 days. Each sprint phase consisted of the presentation of the updated design in BIM to client, client feedback, design development discussions and documentation thereof, and priority-setting for the upcoming sprint phase. The designers then engaged in stand-up meetings/sessions, documenting any design changes made. The chronology and priorities from each Sprint are summarized in Figure 4.

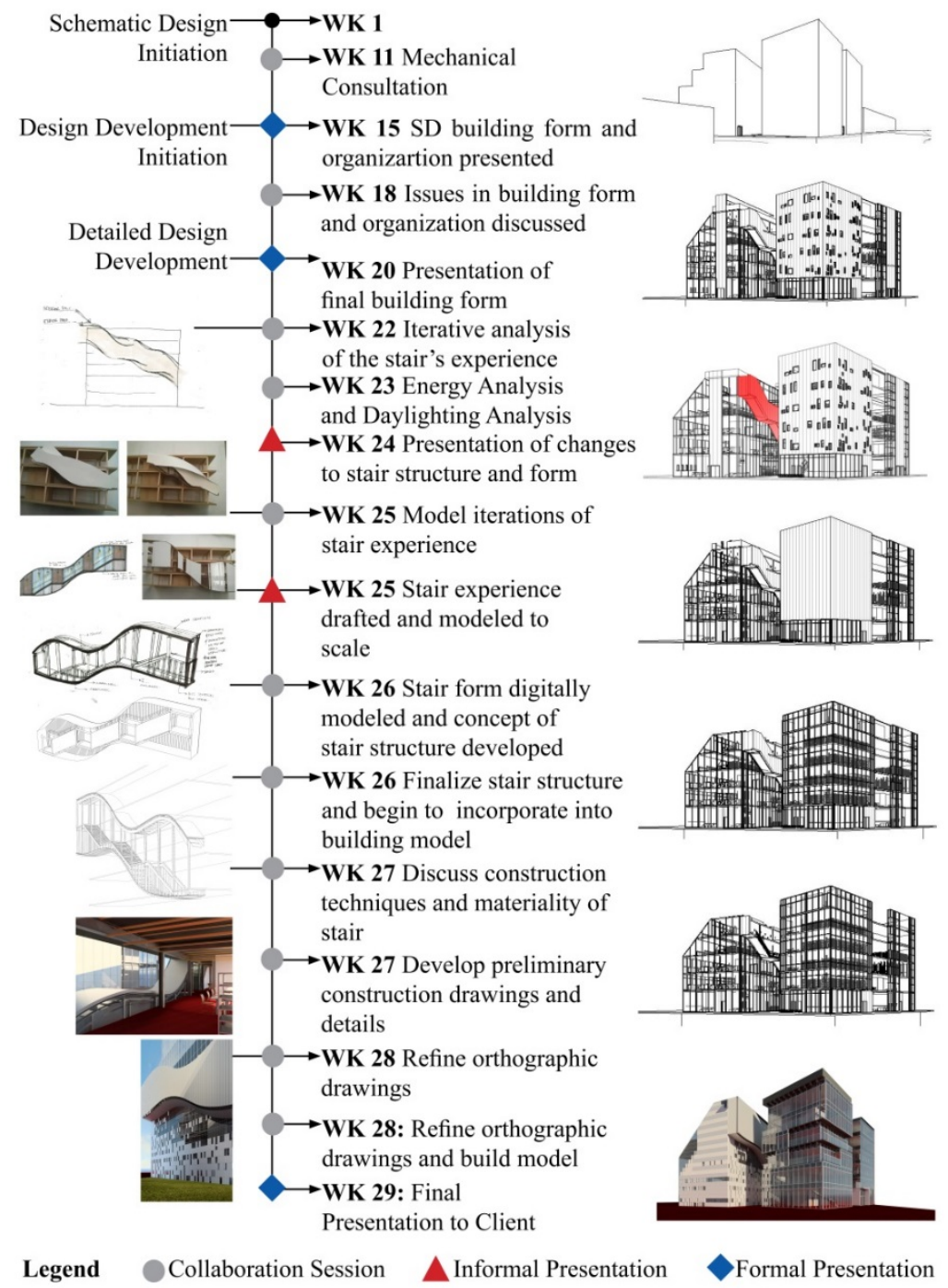

Figure 4: Detailed design development of the stair component. 


\subsection{BIM evolution}

BIM was used to develop and document the design. Several digital BIM tools and non-digital representations of building information used throughout the process as shown in Figure 5.
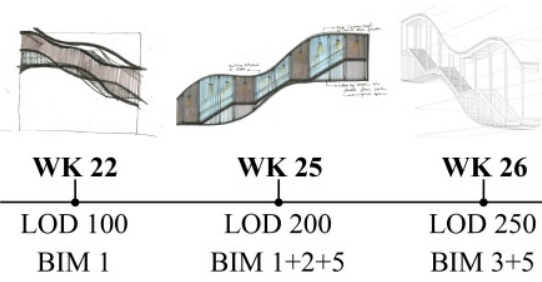
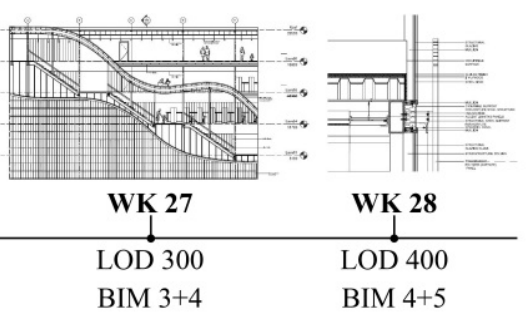

WK 28
LOD 400

BIM $4+5$

Figure 5: Level of development progression.

Initial sprints included iterations of the stair form through Sketches and model making for quick physical documentation of ideas. After agreeing on a sketch form, this was refined using Rhinoceros ${ }^{\mathrm{TM}}$, a 3D form-generation software, which allowed several iterations of design refinement during one Sprint. Once finalized, this form was input to Autodesk Revit ${ }^{\mathrm{TM}}$ and the structural design of the stair was realized. Next, the model complexity was increased to incorporate material properties for the stair and whole building. 2D construction details were generated in AutoCAD ${ }^{\mathrm{TM}}$ based on sections output from the Revit ${ }^{\mathrm{TM}}$ model.

\section{Kerr Hall East: existing building sustainable operations}

Kerr Hall East is an $11,187 \mathrm{~m}^{2}(120,370 \mathrm{sf})$ academic building at Ryerson University, consisting of $38 \%$ labs, $20 \%$ classrooms and $10 \%$ offices. It is the eastern quadrant of the 1962 Kerr Hall building (Figure 6), which has undergone more than 20 partial renovations.

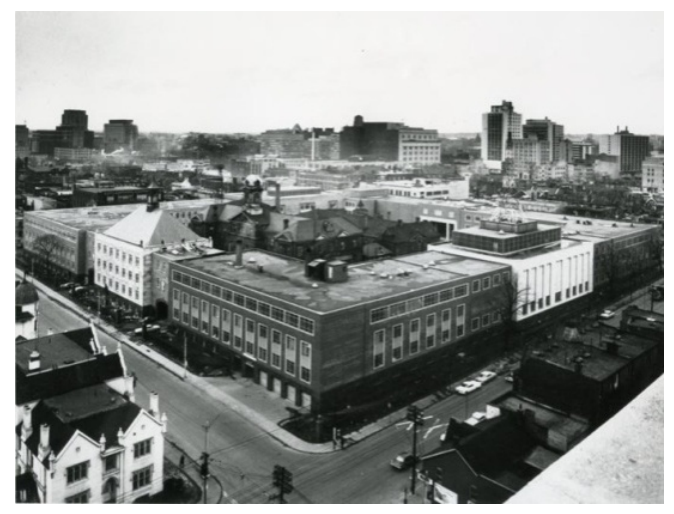

Figure 6: Kerr Hall archival photograph [27]. 
The client was the Campus Facilities and Sustainability (CF\&S) team, who required comprehensive (as-built) building information. In addition, multiple systems and software for each type of campus information (building assessments, maintenance records, health and safety, sustainability, space reporting, etc.) were used, complicating data acquisition for decision-making and planning. To address these needs simultaneously, a BIM for Sustainable Operations is being developed as a pilot study for the whole campus.

The operations BIM study considered the modelling of an existing building at Ryerson University. As this building had already been constructed and operational for over 50 years, the BIM development did not incorporate new design elements per se, instead, the Sprint approaches consisted of (1) identification, implementation and evaluation of new use cases, (2) refinement of the use case implementation approach, and (3) increasing the level of detail of a component in the model. The timeline indicating the collaboration meetings, informal presentations and formal reviews of the BIM are presented in Figure 7.

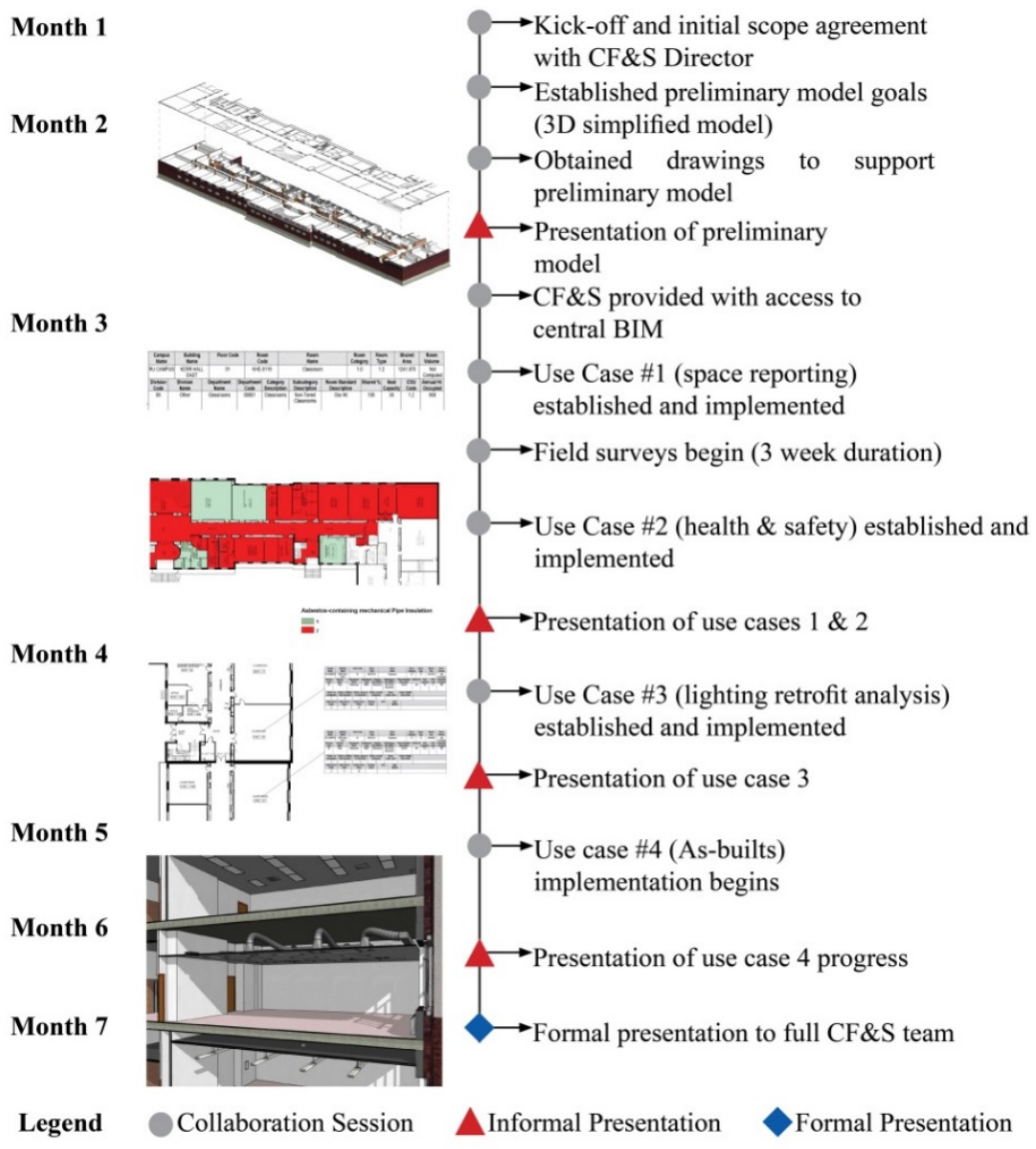

Figure 7: Sprint timeline. 
To obtain demonstrate value to project stakeholders as early in the process as possible, the Sprint process (Figure 1) was applied to the BIM development. The Sprints for this project lasted an average of one month, due to the extensive site surveys and stakeholder coordination required to obtain the necessary data and information for each use case. Six Sprints formed the early work on this model, each starting with a collaborative brainstorming session with CF\&S staff to identify and prioritize beneficial use cases for the BIM an ending with a presentation of the updated model incorporating the new use case. These were: (1) Development of preliminary 3D BIM with simplified geometry (extruded floorplans); (2) Use case 1: space reporting and utilization, incorporating attributes and fields to allow reporting through the centralized space management system; (3) Data collection micro-Sprints (three, each lasting 1 week with lessons learned between each to optimize each successive Sprint); (4) Use case 2: health and safety - asbestos survey results included; (5) Use case 3: sustainability planning quantity of light fixtures and calculation of potential energy savings from retrofit within BIM; and (6) Use case 4: as-built model (excluding concealed elements).

\section{Results}

These case studies demonstrated several benefits from the use of Agile methodologies for BIM model development, particularly in improving communication within the team and with external parties, improving efficiency by minimizing re-work, and reducing client-driven design changes late in the process.

\subsection{Case study \#1: design BIM development}

This case study demonstrated several benefits of Agile Project Management techniques to develop the BIM model. Agile BIM enabled clear communication with the client, and the use of BIM as an integral part of the Sprint process provided a multimodal means to communicate the design intent and progress to the client, resulting in increased precision and consistency in client feedback and direction. The Sprint structure guided client conversation to set priorities and enhance productivity of each Sprint cycle. This increased the level clarity in meetings allowing the client and the designer to achieve a more thorough understanding of the design due to the information provided. The use of multiple BIM for production benefited client and designer's conversation. The Agile Structure allowed client input periodically resulting in clearer communications between client and designer. Ultimately, this reduced re-work and the need for multiple design changes as the client was able to provide input throughout the development phases of the design. Integration of multidisciplinary elements, (e.g. HVAC, sustainability, etc.) was also facilitated by the use of BIM during Sprints focused on this coordination.

Lessons learned from this case study indicated that potential disadvantages of this approach are demonstrated by the early misapplication of the Agile checklists for the Sprint meetings. This was a result of a lack of familiarity with Agile methods, particularly applied to architectural design, by both parties. This issue 
can be mitigated by training participants on a fluid use of these tools as guidelines rather than fixed structures, such that they shape these conversations. A recommended revision to this checklist is included in Section 7.

\subsection{Case study \#2: operations BIM development}

The outcome of this case study was a high level of engagement and client satisfaction. At the final review for the case study project, the client expressed desire to expand the project not only to include the rest of Kerr Hall, but to implement the operations model across the University campus (39 buildings). This high level of engagement was a result of the team's ability to quickly and efficiently create a model that implemented multiple use cases that met the immediate needs of the client.

Because of the use of targeted Sprints, the project ran very efficiently. There was minimal re-work and the total effort to create the model to, with all data collection requiring 150 hours and modelling approximately 250 hours to achieve the results presented in this paper. Because data collection was done in Sprints, these were carried out very efficiently and the documentation (sketches on floorplans and over 2000 photographs mapped to room layouts) has proved valuable for model development beyond the original use cases. Substantial time was spent setting up the model properly and matching with existing CAD drawings, and this has minimized re-work for element modelling. Client-driven changes have also been minimal as each Sprint resulted in a usable model addressing a priority use case, and to date there has been no duplication of effort in the model creation.

\subsection{Recommendations and conclusions}

This paper has demonstrated the benefits of the Agile process applied to the development of BIM models in the design and operations stages. Based on this success, further research into the application of this approach for the development of construction BIM models (i.e. clash detection, fabrication and as-built models) is warranted and anticipated to have similar positive results.

The following questions have been developed from lessons learned in these case studies to guide the Sprint and stand-up meetings. Note that these are not to be considered prescriptive, but are rather to stimulate collaboration and problemsolving discussions by team members.

\begin{tabular}{|c|c|}
\hline Sprint Meetings & Stand-up Meetings \\
\hline $\begin{array}{l}\text { What was the primary goal of the } \\
\text { last Sprint? }\end{array}$ & $\begin{array}{l}\text { What are the outstanding issues for } \\
\text { resolution? }\end{array}$ \\
\hline $\begin{array}{l}\text { What issues arose during the last } \\
\text { Sprint? How were these issues tied } \\
\text { to other design issues? Are other } \\
\text { disciplines or systems affected by } \\
\text { the changes made? }\end{array}$ & $\begin{array}{l}\text { What arose from the last } \\
\text { collaboration session with the client? } \\
\text { Are there any issues that may affect } \\
\text { other disciplines or systems? }\end{array}$ \\
\hline
\end{tabular}




\begin{tabular}{ll}
\hline $\begin{array}{l}\text { What new issues require discussion } \\
\text { during this collaboration session/ } \\
\text { meeting? }\end{array}$ & $\begin{array}{l}\text { How will tasks for this Sprint be } \\
\text { assigned amongst the team? }\end{array}$ \\
\hline $\begin{array}{l}\text { What are the priorities for the next } \\
\begin{array}{l}\text { Sprint? How will success be } \\
\text { measured? }\end{array}\end{array}$ & $\begin{array}{l}\text { What will each team member have } \\
\text { ready for the next stand-up meeting? }\end{array}$ \\
\hline $\begin{array}{l}\text { Are there any other issues } \\
\text { (backlog) requiring attention? }\end{array}$ & $\begin{array}{l}\text { What level of development will be } \\
\text { produced for revised BIM elements? }\end{array}$ \\
\hline
\end{tabular}

\section{Acknowledgements}

The authors would like to thank the Ryerson University Campus Facilities and Sustainability Team for their cooperation and input to Operations model case study, and Professor Jeff Geldart and Alvin Tanako from Ryerson University for their participation and valuable contributions to the design case study.

\section{References}

[1] Kreider, R., Messner, J. \& Dubler, C. Determining the Frequency and Impact of Applying BIM for Different Purposes on Building Projects. Proceedings of the 6th International Conference on Innovation in Architecture, Engineering and Construction, eds. C.J. Anumba, N.M. Bouchlaghem, J.I. Messner, and M.K. Parfitt, Loughborough University, UK, 2010.

[2] Becerik-Gerber, B. \& Kensek, K. Building Information Modeling in Architecture, Engineering, and Construction: Emerging Research Directions and Trends. J. Prof. Issues Eng. Educ. Pract., 136(3), pp. 139$147,2011$.

[3] Sebastian, R. Changing roles of the clients, architects and contractors through BIM. Engineering, Constr. Arch. Manag., 18(2), pp.176-187, 2011.

[4] Computer Integrated Construction (CIC) Research Program. (2011). BIM Project Execution Planning Guide - Version 2.1. Pennsylvania State University, University Park, PA, USA.

[5] Beck K, et al., Manifesto for agile software development; 2001. Online. http://agilemanifesto.org

[6] Manning, R. \& Messner, J. I. Case studies in BIM implementation for programming of healthcare facilities. J. Inf. Technol. Constr., 13, pp. 446457, 2008.

[7] Zuppa, D., Issa, R. R. A. \& Suermann, P. C. BIM's impact on the success measures of construction projects. Proc. 2009 ASCE Int. Workshop on Computing in Civil Engineering, eds. Caldas, C.H. \& O'Brien, W. J., Technical Council on Computing and Information Technology of ASCE, Reston, VA, pp. 503-512, 2009.

[8] Wong, K. \& Fan, Q. Building information modelling (BIM) for sustainable building design. Facilities, 31(3/4), pp. 138-157, 2013. 
[9] Grilo, A. \& Jardim-Goncalves, R. Value proposition on interoperability of BIM and collaborative working environments. Automation in Construction 19(5), pp. 552-530, 2010.

[10] Azhar, S. \& Brown, J. BIM for Sustainability Analyses. International Journal of Construction Education and Research, 5(4), pp. 276-292, 2009.

[11] Krygiel, E., and Nies, B. Green BIM: Successful sustainable design with building information modeling, Wiley, Indianapolis, 2008.

[12] Kota, S., Haberl, J. S., Clayton, M., J \& Yan, W. Building Information Modeling (BIM)-based daylighting simulation and analysis. Energy and Buildings, 81, pp. 391-403, 2014.

[13] Ho, S., Tserng, H. \& Jan, S., (2013) Enhancing Knowledge Sharing Management Using BIM Technology in Construction, The Scientific World Journal, 2013 (Article ID 170498), 2013.

[14] Becerik-Gerber, B., Jazizadeh, F., Li, N. \& Calis, G. Application Areas and Data Requirements for BIM-Enabled Facilities Management. J. Constr. Eng. Manage., 138(3), pp. 431-442, 2012.

[15] Jiang, S., Zhang, H., Zhang, J. Research on BIM-based Construction Domain Text Information Management. J. Networks, 8(6), pp. 1455-1464, 2013.

[16] Conforto, E. C., Salum, F., Amaral, D. C., da Silva, S. L. \& de Almeida, L. F. M. Can Agile Project Management Be Adopted by Industries Other than Software Development? Project Management Journal, 45, pp. 21-34, 2014.

[17] Freire, J. \& Alarcón, L. F. Achieving lean design process: Improvement methodology. J. Constr. Eng. Manage., 128:3(248), pp. 248-256, 2002.

[18] Arayici, Y., Coates, P., Koskela, L., Kagioglou, M., Usher, C. \& O’Reilly, $\mathrm{K}$. Technology adoption in the BIM implementation for lean architectural practice, Automation in Construction, 20(2), pp. 189-195, 2011.

[19] Pektaş, S. T. \& Pultar, M. Modelling detailed information flows in building design with the parameter-based design structure matrix. Design Studies, 207 (1), pp. 99-122, 2006.

[20] Hasan, M.A., Shankar, R., Sarkis, J., Suhail, A. \& Asif, S. A study of enablers of agile manufacturing. Int. J. Indus. Sys. Eng., 4(4), pp. 407-430, 2009.

[21] Gunasekaran, A. Agile manufacturing: a framework for research and development. Int. J. Production Economics, Vol. 62, pp. 87-105, 1999.

[22] Cobb, C. The project manager's guide to mastering agile principles and practices for an adaptive approach. John Wiley \& Sons, Hoboken, 2015.

[23] Ryerson University Archives, RG 4-116, Folder 4, ca. 1962. 